\title{
RECONSTITUIÇÃO GEOMORFOLÓGICA DE PLANÍCIES FLUVIAIS URBANIZADAS: O CASO DO RIO PINHEIROS, SÃO PAULO-SP
}

\section{GEOMORPHOLOGICAL RECONSTITUTION OF URBANISED FLUVIAL PLAINS: THE CASE OF PINHEIROS RIVER, SAO PAULO-SP}

\author{
Rodolfo Alves da Luz \\ Programa de Pós-Graduação em Geografia Física - Departamento de Geografia, Faculdade de Filosofia Letras e \\ Ciências Humanas, Universidade de São Paulo - São Paulo - SP-Brasil. \\ E-mail: rodolfo.luz@usp.br
}

Cleide Rodrigues

Departamento de Geografia, Faculdade de Filosofia Letras e Ciências Humanas, Universidade de São Paulo.

E-mail: cleidrig@usp.br

\section{Informações sobre o Artigo}

Data de Recebimento:

27/09/2012

Data de Aprovação:

$17 / 05 / 2013$

\section{Palavras-chave:}

Geomorfologia fluvial; cartografia geomorfológica; gestão territorial urbana.

\section{Keywords:}

Fluvial geomorphology; geomorphologic mapping; urban land management.

\begin{abstract}
Resumo
Este estudo trata da proposição e aplicação de técnicas para reconhecimento da geomorfologia original de planícies fluviais urbanizadas utilizando-se de procedimentos tradicionais e da abordagem histórica em geomorfologia. Tem como foco o reconhecimento de uma paleogeografia e de uma paleogeomorfologia de um trecho do rio Pinheiros, na cidade de São Paulo em seu estágio pré-urbano holocênico com algumas incursões ao Pleistoceno Superior. Dentre os principais resultados destaca-se a produção da carta geomorfológica de detalhe na escala 1:20.000 e a análise de sua aplicação em demandas da gestão territorial urbana. Foram utilizados princípios da cartografia geomorfológica de detalhe, da antropogeomorfologia e da abordagem histórica em geomorfologia (Nir 1983, Goudie, 1997, Rodrigues 2001, Gurnell et al. 2003, e Trimble 2008), realizando-se pesquisa arquivística, fotointerpretação, trabalho de campo, análise de mapas antigos e de dados pedo-estratigráficos disponíveis em recentes relatórios de engenharia do Metrô de S. Paulo. A articulação destes dados em representações espaciais bi-dimensionais permitiu a reconstituição de uma sequência de eventos geomorfológicos atuantes no sistema fluvial no Holoceno e no Pleistoceno Superior. Foi identificada significativa influência da estrutura geológica na evolução holocênica da planície. Por outro lado, identificou-se paleocanal preenchido por depósitos da Formação Itaquaquecetuba que evidenciaram a existência de fluxos fluviais de maior potência comparativamente ao dos canais meândricos holocênicos. Demonstrou-se também a relevância deste conhecimento paleogeográfico e geomorfológico para a gestão territorial urbana e análise de riscos geotécnicos.
\end{abstract}


Upper Pleistocene. The main results were the detailed morphologic map in 1:20,000 and the evaluation of its application in urban land management. Principles from detailed geomorphological mapping, anthropogeomorphology and historical geomorphology were utilised (Nir 1983, Goudie, 1997, Rodrigues 2001, Gurnell et al. 2003, and Trimble 2008), performing archival surveys, interpretation of old aerial photographs and maps, field surveys and analysis of the pedological and stratigraphic data obtained from engineering reports from Sao Paulo Underground. The articulation of these data in spatial representations conducted to the reconstitution of a sequence of geomorphological events operating in the fluvial system during the Holocene and Upper Pleistocene. Significant influences of the geological structure in the Holocene evolution of the system were identified. A paleochannel filled by Itaquaquecetuba Formation deposits, dating of the Upper Pleistocene, which are compatible with higher power flows than the Holocene meandering channel was also identified by this study. The relevance of the results of that approach to urban land management and geotechnical evaluations were also demonstrated in this paper.

\section{Introdução}

A caracterização morfológica de sistemas fluviais associada à descrição dos materiais (litologia, solos e depósitos tecnogênicos) permite a interpretação de seus processos predominantes, sejam estes característicos de fases anteriores, contemporâneas ou posteriores às intervenções humanas (Hart, 1986).

A utilização destas análises em seus aspectos evolutivos quaternários - de longa duração - e históricos - curta duração - tem sido considerada fundamental, tanto para a avaliação de mudanças ambientais, como para a compreensão dos novos balanços e mecanismos que se instauram em áreas antropizadas (Rodrigues 1999, 2001,2004, 2010). Estas análises igualmente têm demonstrado sua relevância na prospecção de cenários de riscos, principalmente, em áreas urbanas, conforme considerações de diversos autores, tais como: Gregory \& Walling (1987); Douglas (1978 e 1983); Gupta \& Ahmad (1999); Douglas \& Lawson (2000); Gupta (2002) e; Alcántara-Ayala \& Goudie (2010).

Esta pesquisa insere-se no conjunto destas novas tendências de investigações geomorfológicas, denominadas recentemente de geomorfologia retrospectiva (Ab'Saber apud Rodrigues 2005), de geomorfologia antropogênica (Nir 1983; Rodrigues 1999), da abordagem histórica em geomorfologia (Gurnell et al. 2003; Trimble 2008) e da geomorfologia urbana (Douglas 1983; Douglas \& Lawson 2000).

Considerando o intenso e relativamente recente processo de urbanização de São Paulo, estudos geomorfológicos retrospectivos nestas áreas, que integrem espacialmente a história natural e antrópica de suas paisagens, permitem recuperar e gerar informações importantes, aprofundando e ampliando o reconhecimento de novas variáveis, conhecimento este aplicável a estudos de geografia urbana, avaliações de risco, estudos geotécnicos e de planejamento territorial.

Do ponto de vista específico da morfologia da planície fluvial meândrica original, seu reconhecimento integrado às informações geradas por obras de engenharia, puderam acrescentar novas perspectivas para interpretações sobre a evolução quaternária e até mesmo terciária deste sistema fluvial, hoje camuflado pela urbanização da cidade de São Paulo.

O objetivo principal deste estudo foi descrever e mapear a morfologia fluvial característica da fase pré-urbana de parte do sistema meândrico do rio Pinheiros em São Paulo, correlacionando-a espacialmente aos materiais que a sustentam. Foram identificados materiais de origem antrópica e formações superficiais e solos originais, e, estes últimos discriminados dos materiais mais antigos subjacentes, possibilitando, assim, a proposição de interpretações morfogenéticas e morfodinâmicas da área.

$\mathrm{Na}$ reconstituição geomorfológica foram utilizadas aerofotos de arquivos históricos identificados nas pesquisas de Rodrigues (2001) e Carvalho (2006) em escalas de 1:5.000, 1:12.500 e 1:25.000. Para a identificação dos materiais superficiais e solos foram compilados dados de sondagens geológicas executadas pela Companhia do Metropolitano de São Paulo - Metrô e pela Construtora São José Ltda. entre 2004 e 2007, além de levantamentos de campo em materiais expostos por escavações de obras subterrâneas em andamento.

\section{Área de Estudo}

A área de estudo corresponde a uma parte da planície fluvial do rio Pinheiros entre os bairros de Pinheiros, Butantã e Cidade Jardim na cidade de São Paulo (Figura 1). Esta região é caracterizada por ocupação urbana densa, que tem modificado drasticamente suas características geomorfológicas originais. Desde o início do século XX a planície fluvial foi bastante modificada por cavas de mineração de areia (até meados de 1950), obras de canalização e retificação do canal (década de 1930), aterramentos (principalmente a partir de 1960) e construção de edifícios e túneis (principalmente a partir de 1970/80).

A planície fluvial do rio Pinheiros localiza-se na borda ocidental da Bacia Sedimentar de São Paulo, fazendo contato a oeste e sul com os afloramentos do embasamento pré-cambriano. No trecho estudado, o embasamento aflorante a oeste é composto por migmatitos, xistos e gnaisses e é compartimentado por dois blocos tectônicos delimitados pela Falha de Caucaia (Hasui \& Carneiro 1980). A Bacia de São Paulo é preenchida por sedimentos cenozóicos, representados na área principalmente pela Formação Resende e, secundariamente, pelas Formações São Paulo e Itaquaquecetuba (Riccomini et al. 2004) (Figura 1 e Figura 2). 


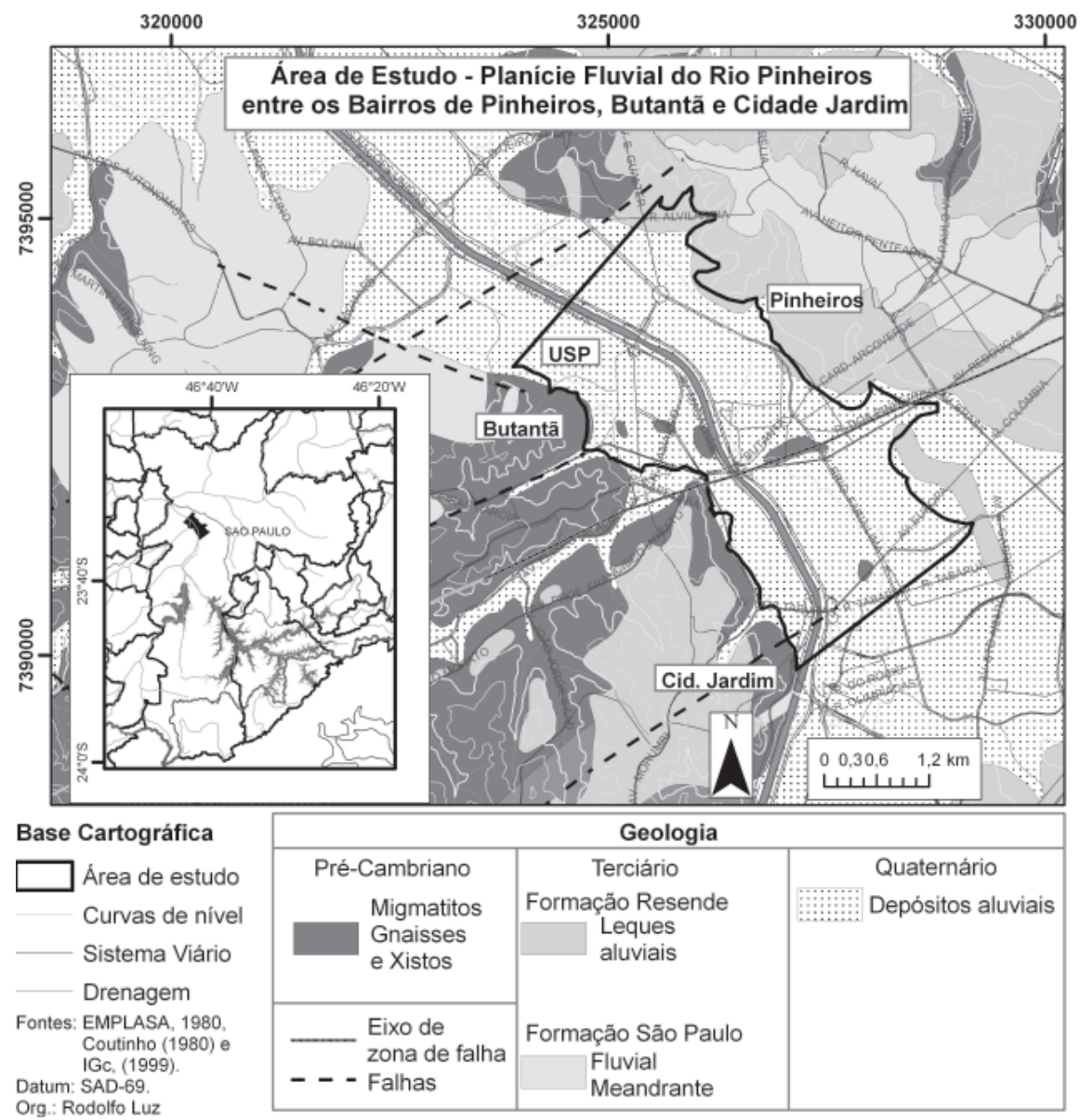

Figura 1 - Localização e aspectos geológicos da área de estudo.

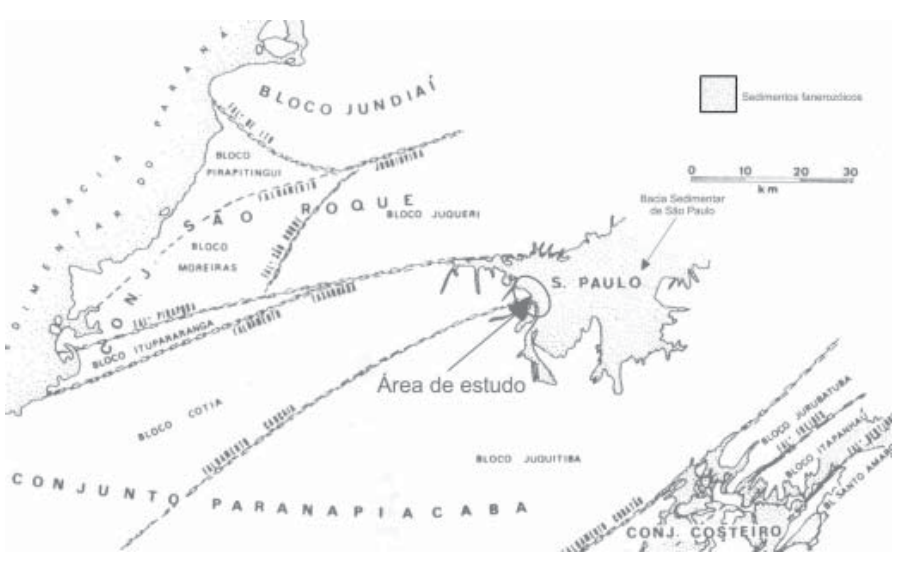

Figura 2 - Compartimentação tectônica do embasamento précambriano no entorno da Bacia Sedimentar de São Paulo com destaque para a área de estudo. Fonte: Hasui \& Sadowski (1980).

A Formação Itaquaquecetuba é definida como depósitos típicos de sedimentação fluvial de padrão entrelaçado, relacionados às drenagens precursoras dos rios Tietê e Pinheiros estabelecidas sob controle de microbacias tectônicas alongadas transtracionais (Suguio et al. 2010). Ela é composta, basi- camente, por arenitos grossos arcoseanos com estratificações cruzadas tabulares e estruturas acanaladas, podendo conter níveis argilo-siltosos e níveis de conglomerados com seixos, atingindo espessuras superiores a 40 metros (Riccomini et al.1992; Takiya, 1997).

Apesar de ser admitida idades terciárias para a Formação Itaquaquecetuba (Melo et al., 1985; Lima et al., 1991; Arai \& Yamamoto, 1995; Santos, et al., 2010), datações recentes apresentadas por Suguio et al (2010) sugerem que sua deposição ocorreu no último máximo glacial durante o Pleistoceno (47.000 \pm 6.000 a $89.000 \pm 12.000$ anos), suportando as interpretações pioneiras de Bigarella (1971), Suguio (1971) e Ab'Saber (1978).

Os sedimentos quaternários da planície fluvial do rio Pinheiros raramente ultrapassam os 10 metros de espessura (Takiya 1997) e apresentam camadas basais de cascalhos e seixos; areias finas, médias e, por vezes, grossas a conglomeráticas nas porções intermediárias; e camadas turfosas no topo. Estes sedimentos estão recobertos por depósitos tecnogênicos, que compõem aterros com 2 metros ou mais de espessura, sobrepostos à planície de inundação original (Carvalho 2006). 
A planície fluvial do rio Pinheiros na área de estudo é delimitada na sua margem direita pelas colinas sedimentares da Bacia de São Paulo e na sua margem esquerda, pelos morros do embasamento cristalino. A compartimentação geomorfológica desta parte da planície foi descrita em Ab'Saber (1957), que identificou um nível de terraços localizado entre 724 e 740 metros de altitude de ocorrência generalizada na margem direita do rio, e dois níveis de planícies de inundação, um atingido somente pelas grandes cheias localizado entre 722 e 724 metros, e outro atingido pelas inundações anuais entre 719 e 721 metros (Figura 3).

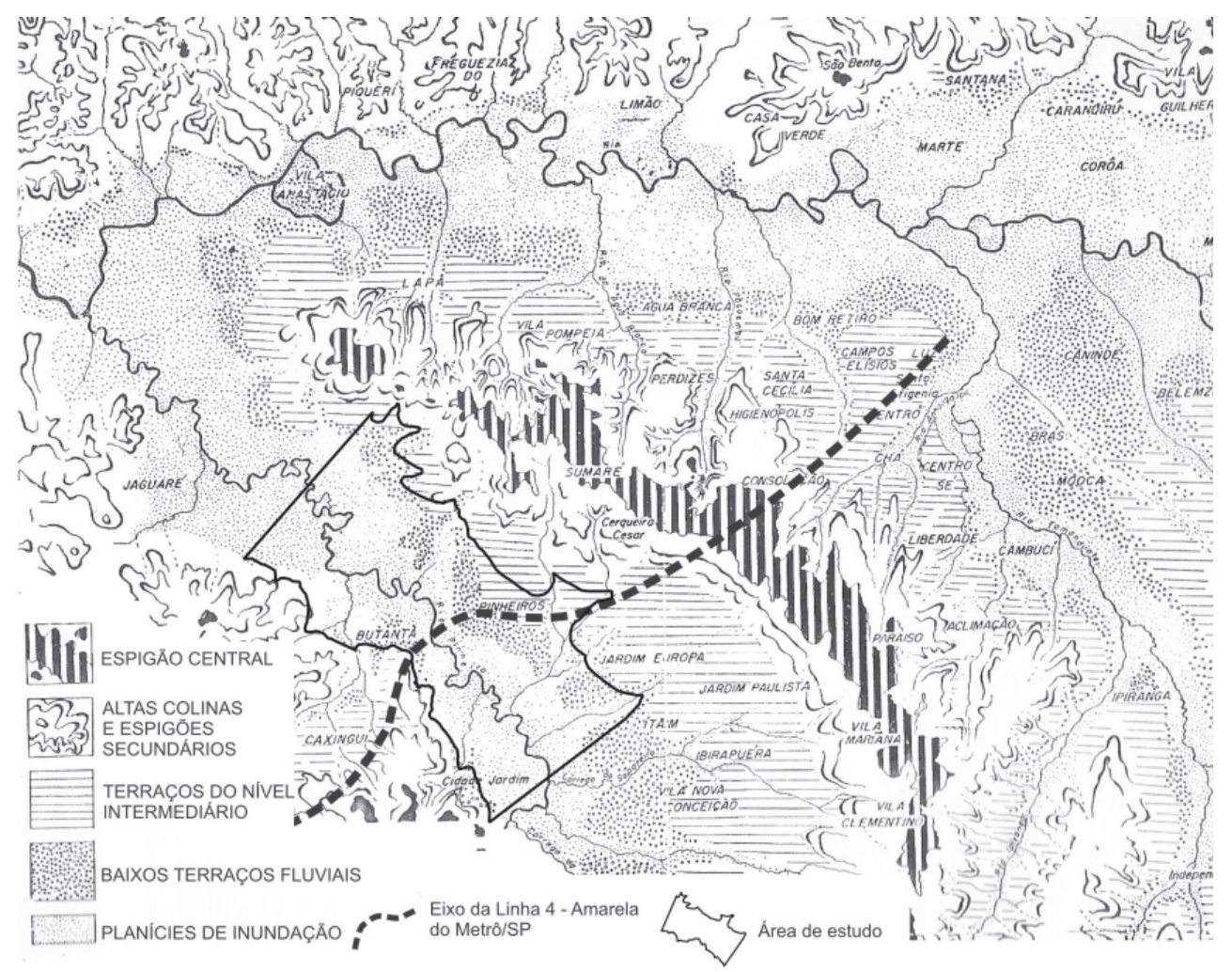

Figura 3-Reconhecimento geomorfológico em 1:50.000 da área de estudo (Ab'Saber 1957).

\section{Materiais e Métodos}

A reconstituição geomorfológica foi concebida nos moldes das tradicionais cartas geomorfológicas de detalhe, nas quais os conteúdos morfométricos, morfográficos e morfológicos são correlacionados às informações do embasamento e aos processos atuais e pretéritos (Tricart 1965; Démek 1967; Coltrinari 1984).

A definição de conteúdos da legenda foi realizada a partir de uma primeira estruturação baseada nos estudos de Santana (2008). Esta sistematização considerou os três subsistemas hidromorfodinâmicos mais comuns de planícies fluviais meândricas, tendo em vista os processos fluviais dominantes na gênese da unidade morfológica e os depósitos resultantes, a saber:

- Subsistema do canal: canal ativo, barras de acresção lateral e meandros abandonados, entendidos aqui como morfologias geradas por processos de canal que ainda não foram completamente incorporadas a planície de inundação, uma vez que apresenta marcas evidentes de atividade recente de canal fluvial;

- Subsistema da planície de inundação: cordões marginais convexos sub-atuais, diques marginais, backswamps, crevasses.

- Subsistema dos terraços fluviais: terraço capeado por sedimentos quaternários e terraço localizado diretamente sobre o embasamento rochoso.

A representação cartográfica destas unidades baseou-se em conteúdos específicos dos elementos fluviais em legendas de diversas propostas de mapeamento morfológico, tais como: Savigear (1965); Tricart (1965); Coutard et al. (1978); Coltrinari (1982); Dackombe \& Gardiner (1983); Hart (1986); Lima (1990); Estaiano (2007); Santos et al. (2008). Porém, devido à escala adotada, o maior detalhamento da morfologia fluvial e de sua representação foi orientado pelo estudo de Santana (2008). 
As principais bases cartográficas utilizadas para o mapeamento foram: SARA BRASIL (1930), e EMPLASA (1972/74/80/81 e 1984). As fotografias aéreas utilizadas constam na Tabela 1.

\begin{tabular}{|c|c|c|c|c|c|}
\hline Data & Levantamento & Escala & Faixa / Região & $\mathrm{N}^{\circ}$ das fotografias & Fonte \\
\hline 1933 & Serviço 62. & $1: 5.000$ & $\begin{array}{l}\text { Rio Pinheiros e } \\
\text { bairros } \\
\text { adjacentes. }\end{array}$ & $\begin{array}{l}35.785 \text { a } 35787 \text { e } \\
\text { 35794 a } 35810 .\end{array}$ & $\begin{array}{l}\text { Fundação Energia e } \\
\text { Saneamento }\end{array}$ \\
\hline 1938 & Serviço 58. & $1: 5.000$ & $\begin{array}{l}\text { Região da Praça } \\
\text { Panamericana. }\end{array}$ & $\begin{array}{l}142,143,145,146 \mathrm{e} \\
188\end{array}$ & $\begin{array}{l}\text { Fundação Energia e } \\
\text { Saneamento }\end{array}$ \\
\hline 1949 & Serviço 12 & $1: 12.500$ & $\begin{array}{l}\text { Rio Pinheiros e } \\
\text { bairros } \\
\text { adjacentes. }\end{array}$ & $\begin{array}{l}06 \text { a } 20,31,38,59 \mathrm{e} \\
60\end{array}$ & $\begin{array}{l}\text { Fundação Energia e } \\
\text { Saneamento }\end{array}$ \\
\hline $1953 / 54$ & $\begin{array}{l}\text { Cidade de São } \\
\text { Paulo. }\end{array}$ & $1: 25.000$ & Faixas 3,4 e 5 & $55,68,70,95$. & $\begin{array}{l}\text { Arquivo de } \\
\text { Fotografias Aéreas } \\
\text { do DG-FFLCH-USP } \\
\text { (AFA-USP) }\end{array}$ \\
\hline
\end{tabular}

Tabela 1 - Fotografias aéreas utilizadas na restituição morfológica.

O principal levantamento aerofotográfico utilizado foi o de 1933, por ser o de maior escala (1:5.000), o mais antigo e no qual a morfologia com baixo nível de perturbação é mais evidente. Além disto, este levantamento apresenta sobreposição mais adequada para a montagem de pares estereoscópicos. As aerofotos restantes foram utilizadas apenas para resolução de dúvidas localizadas e para a restituição morfológica de compartimentos maiores, como os terraços. Assim, existem dois níveis de detalhamento na área mapeada.

Foram realizados levantamentos de campo para conferir e sistematizar informações morfológicas obtidas pela fotointerpretação, focalizando pontos de dúvidas e de descontinuidades morfológicas.

As informações a respeito dos materiais, ou seja, formações rochosas aflorantes, solos, depósitos tecnogênicos e algumas rochas subjacentes foram obtidas a partir de releituras e reinterpretações de informações de sondagens geológicas de obras subterrâneas realizadas na área, principalmente as do Metrô de São Paulo. Esses dados foram compatibilizados com revisão bibliográfica e trabalhos de campo.

As campanhas de campo, que tiveram por objetivo a caracterização dos materiais, foram realizadas em escavações do próprio Metrô e em outras obras que estavam em andamento na área entre 2008 e 2010. Estas campanhas envolveram descrições de perfis verticais quanto a alguns aspectos morfológicos, tais como transição entre níveis/horizontes, cor, textura e estrutura.

A consideração deste nível de informação e sua articulação às representações cartográficas elaboradas permitiram a produção de um perfil morfo-sedimentológico transversal da planície.

A análise geomorfológica pautou-se nos preceitos da Geomorfologia Fluvial, especificamente no que diz respeito aos sistemas meândricos, principalmente a partir de Leopold et al. (1964), Christofoletti (1974 e 1981), Suguio \& Bigarella (1990), Cunha (1994), Miall (1996), Knighton (1998) e Bridge (2003).
Esta análise foi realizada por meio da correlação espacial entre a morfologia da planície (identificada na fotointerpretação) e as materiais (identificadas no perfil morfosedimentológico). Essa correlação possibilitou interpretações dos processos geomorfológicos atuantes em cada unidade morfológica fluvial da planície holocênica e, até mesmo, de eventos pleistocênicos.

No que se refere ao Holoceno e Pleistoceno Superior foi possível reconstruir parte de cenários hidromorfodinâmicos, incluindo a provável identificação de sistemas fluviais com fluxos de maior potência que os fluxos caracteristicamente meândricos.

\section{Resultados}

A Carta Geomorfológica da Planície Fluvial Meândrica do Rio Pinheiros entre os Bairros de Pinheiros, Butantã e Cidade Jardim é apresentada na Figura 4 e sua legenda na Figura 5. A área mapeada compreendeu cerca de $11 \mathrm{~km}^{2}$ da planície fluvial do rio Pinheiros e de parte de seus afluentes, sendo o rio Pirajussara o de maior expressão neste trecho. Os terrenos compreendidos em sistemas de vertente adjacentes foram articulados ao mapeamento realizado por Ab'Saber (1957) em 1:50.000.

A planície fluvial é mais extensa na margem direita original, onde há uma mudança em forma de rampa com as vertentes adjacentes. Somente no extremo nordeste da área mapeada é que o limite da planície com o sistema vertente é abrupto, formando uma ruptura com as altas colinas e espigões secundários situados sobre os sedimentos terciários da Bacia Sedimentar de São Paulo.

Já na margem esquerda ocorre uma generalizada ruptura entre a planície fluvial e os morros sustentados pelas rochas do embasamento pré-cambriano. Esta ruptura é descontínua somente quando a planície fluvial do rio Pirajussara coalesce com a planície do rio Pinheiros.

Os terraços fluviais são contínuos e extensos na margem direita da planície e descontínuos e pouco extensos na esquerda. Os primeiros 5 metros da estratigrafia dos terraços são compostos por depósitos tecnogênicos, solos e sedimentos quaternários, que estão assentados diretamente sobre o embasamento pré-cambriano alterado ou, nos trechos mais distantes da margem direita, sobre a Formação Resende (Figura 6). No geral, os sedimentos quaternários apresentam uma granodecrescência ascendente e desenvolvimento pedológico no topo.

O perfil morfo-sedimentológico indica que a borda do terraço está assentada diretamente sobre o material de alteração do embasamento pré-cambriano (Figura 6). Segundo Christofoletti (1981) e Goudie (2006), afloramentos do embasamento na borda de terraço é uma das características dos chamados "terraços rochosos" (strath terraces). No caso em questão isso pode indicar que sua morfogênese esteja associada a um entalhamento do canal do rio Pinheiros que ultrapassou os sedimentos fluviais previamente depositados e atingiu este nível do embasamento pré-cambriano. 


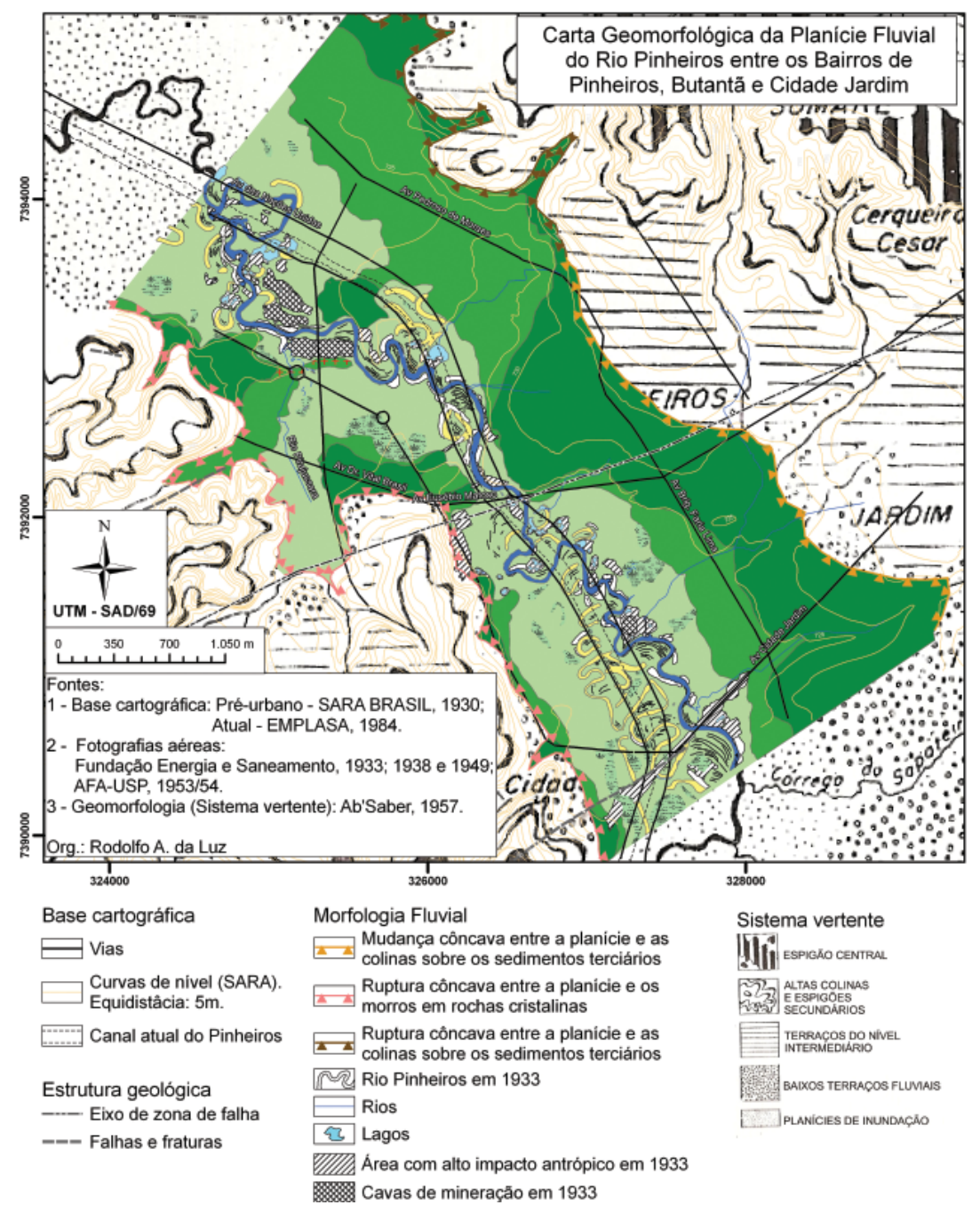

Figura 4 - Carta Geomorfológica da Planície Fluvial do Rio Pinheiros entre os Bairros de Pinheiros, Butantã e Cidade Jardim

Este perfil também evidenciou morfologia típica de provável paleocanal fluvial com mais de 100 metros de largura e pouco mais de 10 metros de profundidade, forma esta preenchida pelos sedimentos da Formação Itaquaquecetuba (Figura 6). Este paleocanal estaria localizado abaixo do canal fluvial meândrico pré-urbano, bem mais estreito, com cerca de 28 metros de largura, e bem mais raso, com cerca de 2 a 3 metros de profundidade ${ }^{1}$.

A planície de inundação apresentava dois níveis altimétricos sem rupturas morfológicas, nível 1 para o mais baixo e nível 2 para o mais alto. O limite entre estes níveis é de difícil identificação, tratando-se de uma mudança suave que ocorre numa faixa de alguns metros. Em alguns locais o nível 2 configura-se como uma rampa suave entre o nível 1 e os terraços fluviais, principalmente na margem direita do

\footnotetext{
${ }^{1}$ Segundo Santos (1958) e Carvalho (2006), a profundidade média do rio Tietê seria de 2 a 3 metros, que aqui assumimos como sendo a profundidade aproximada do rio Pinheiros devido às semelhanças morfométricas de outros parâmetros.
}

rio. Estes dois níveis são compatíveis com a classificação topográfica proposta por Ab'Saber (1957). Os depósitos fluviais holocênicos na planície de inundação possuem de 4 a 7 metros de espessura, e são compostos por sedimentos de grande variedade granulométrica, com predomínio de areias grossas e médias sobre níveis basais de cascalhos e seixos.

Há um avanço dos limites dos terraços fluviais em direção ao canal do rio Pinheiros na região central da carta, tornando a planície de inundação mais estreita. Este setor coincide com o local onde um eixo de zona de falha atravessa transversalmente a planície fluvial. De uma extensão lateral média de 1400 metros, a planície de inundação é reduzida neste ponto para cerca de 190 metros. Esta região vincula-se à Falha de Caucaia que delimita dois blocos tectônicos, o bloco de Cotia ao norte e o bloco Juquitiba ao sul, sendo que o primeiro apresentaria menores taxas de subsidência que o segundo, de acordo com Hasui e Sadowski (1976) e Hasui \& Carneiro (1980). 


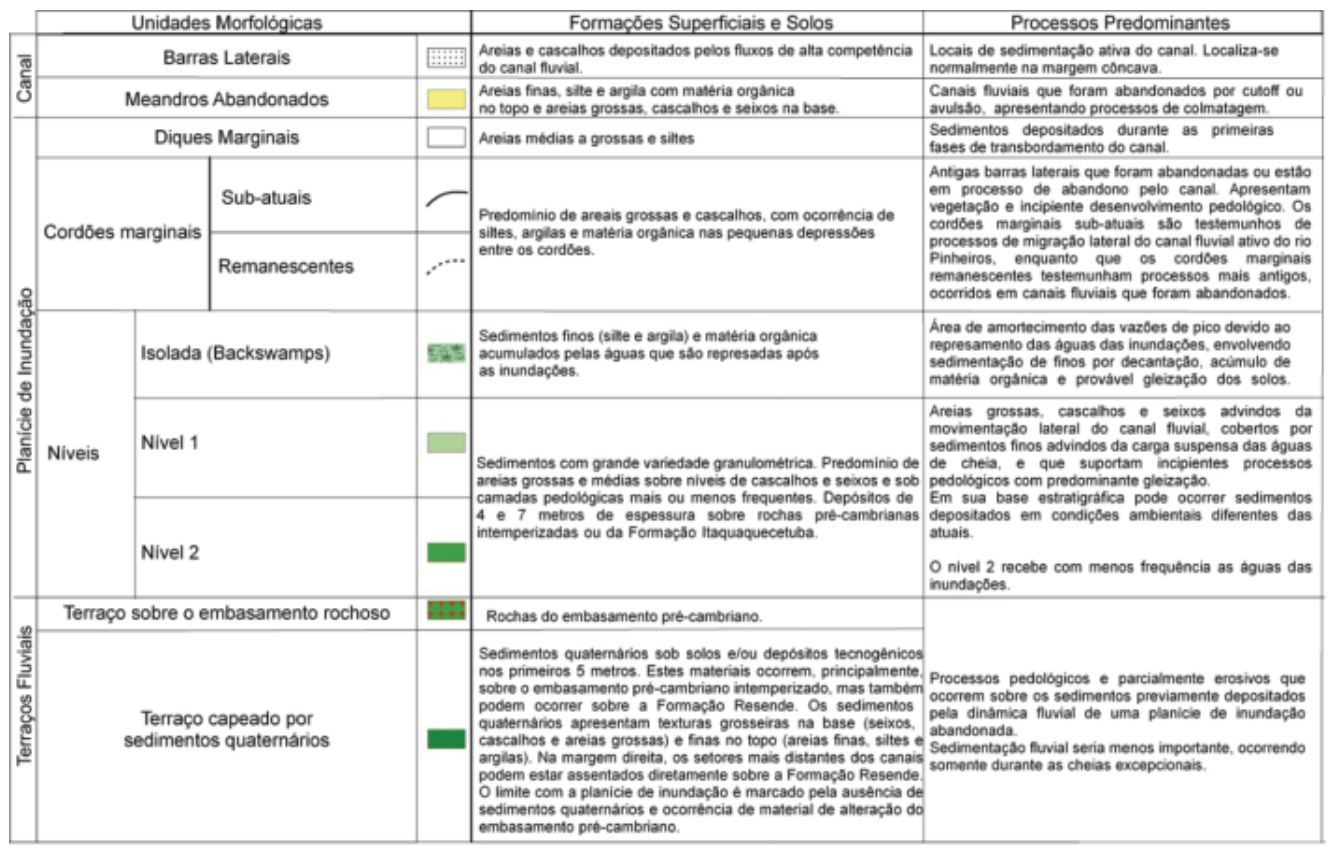

Figura 5 - Detalhamento da legenda da Carta Geomorfológica.
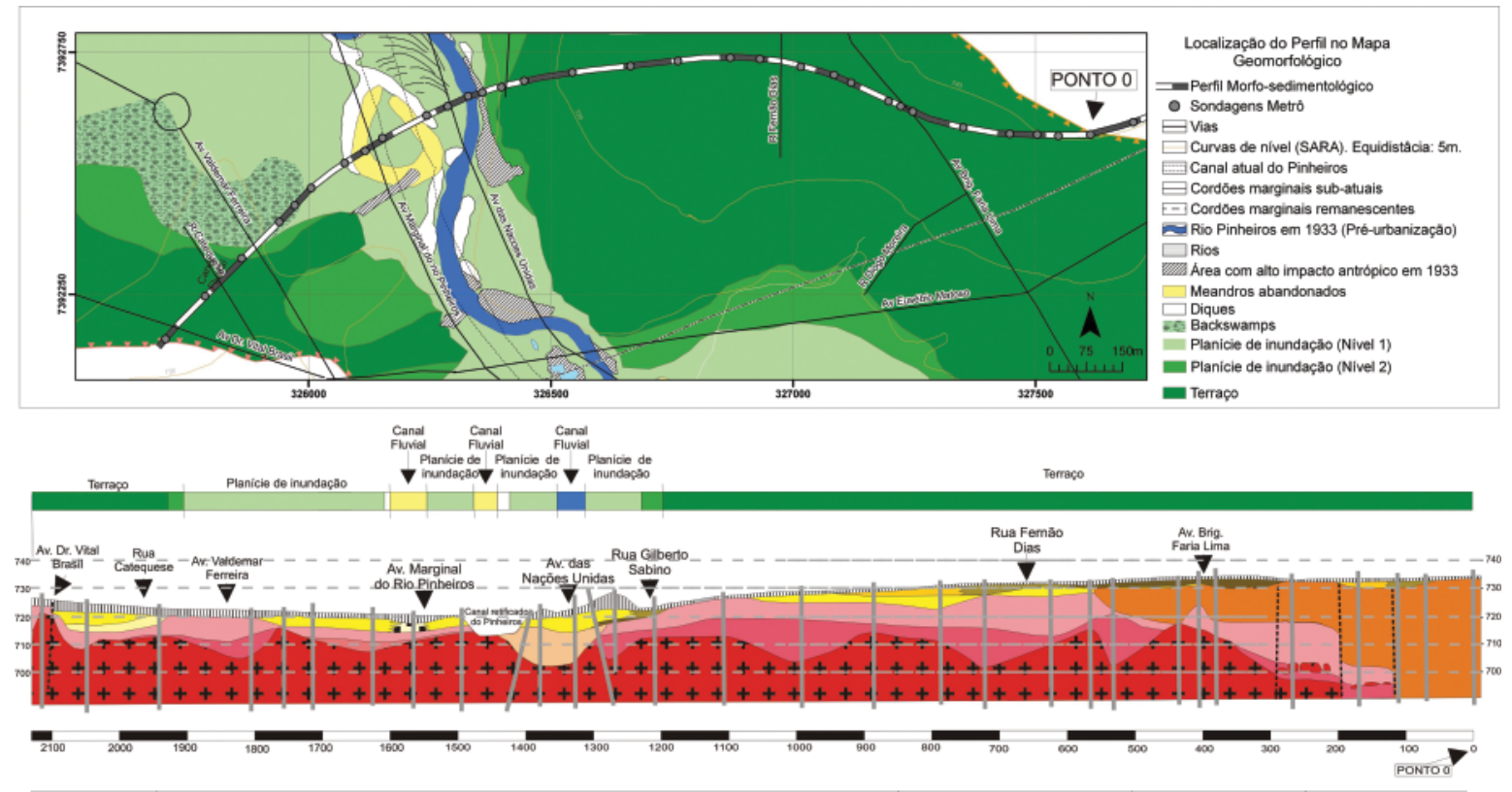

Figura 6 -

Perfil morfosedimentológico da área de estudo

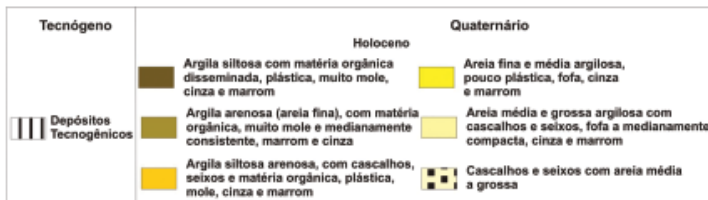

À jusante deste ponto, portanto, já no bloco Cotia, foi possível identificar a presença de terraços isolados dentro da planície de inundação em ambas as margens, enquanto que a montante, no bloco Juquitiba, não há terraços deste tipo. Em determinados locais foi possível verificar em campo que alguns destes terraços isolados correspondem a afloramentos do embasamento rochoso, o que permitiu a sua classificação como terraço estrutural. Além disso, por meio da análise dos meandros abandonados, verifica-se que no trecho à montante

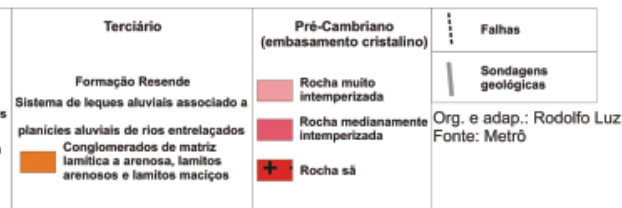

ocorreram significativos processos de avulsão do canal, diferentemente do trecho à jusante.

\section{Discussão}

Em relação a aspectos morfogenéticos, a análise da carta permitiu a realização de algumas interpretações. Em locais próximos ao trecho de estreitamento da planície de inundação 
há um eixo de zona de falha que pode estar delimitando dois blocos tectônicos com distintos graus de subsidência (concordando com Hasui e Sadowski 1976 e Hasui \& Carneiro 1980). À jusante deste ponto, a menor subsidência do bloco Cotia pode ser correlacionada à ocorrência de afloramentos do embasamento pré-cambriano dentro da planície de inundação, morfologicamente representados pelos terraços sobre o embasamento rochoso.
A morfologia da planície fluvial do rio Pinheiros pode estar refletindo significativa influência de aspectos estruturais da geologia regional e local, tendo em vista os diferentes graus de subsidência dos dois blocos tectônicos que ali ocorrem (Hasui \& Carneiro 1980). A falha geológica associada ao ponto de estrangulamento da planície de inundação demarca um setor onde a planície fluvial pode ser dividida em dois compartimentos, segundo critérios morfológicos e estruturais (Figura 7):

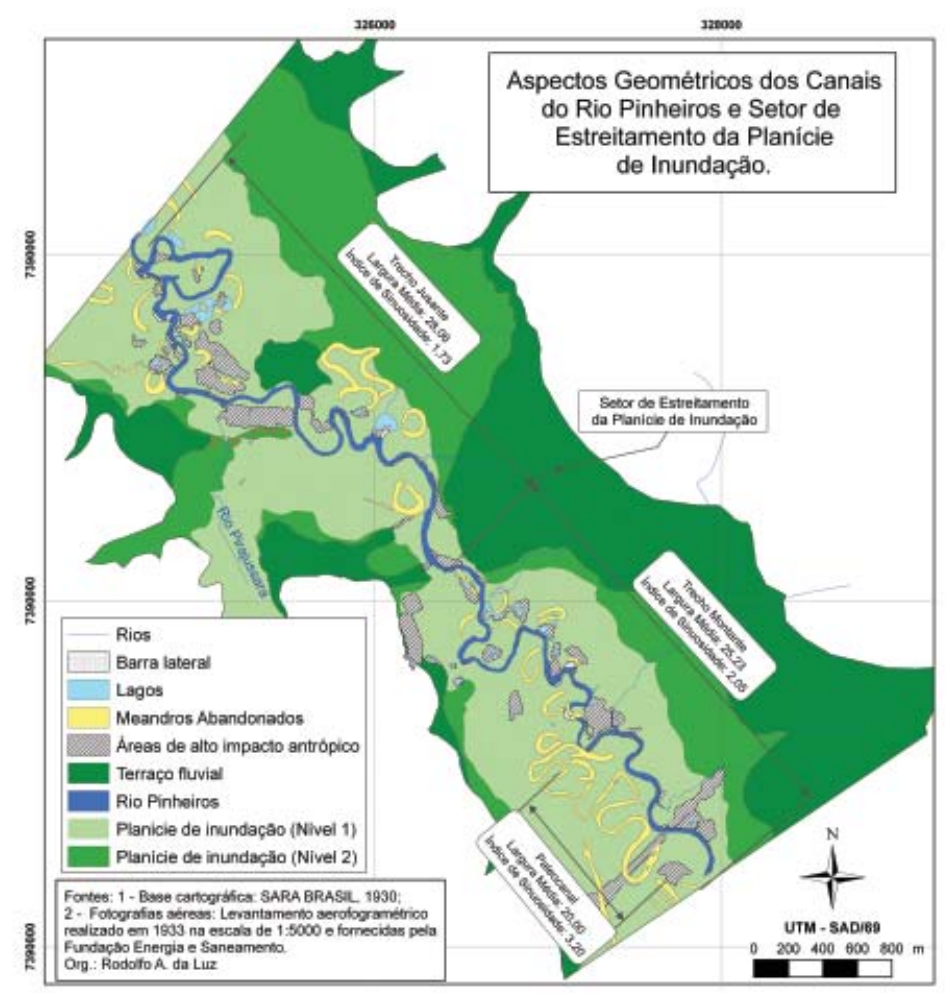

Figura 7 - Aspectos geométricos dos canais ativos e abandonados do rio Pinheiros e ponto de estreitamento da Planície de inundação.

1 - Trecho à montante. Neste, a planície de inundação é ampla e tem as suas unidades mais típicas bem desenvolvidas e de fácil reconhecimento (meandros abandonados, cordões marginais e backswamps). Não se evidenciou terraços sobre o embasamento rochoso, bem como não foram identificadas elevações isoladas e afloramentos do embasamento pré-cambriano. Apresenta significativas diferenças morfológicas entre o canal ativo do rio Pinheiros e um paleocanal provavelmente abandonado por um processo de avulsão.

2 - Trecho à jusante. Neste, a planície de inundação é truncada por falhas geológicas e afloramentos do embasamento pré-cambriano algumas vezes em forma de terraços. As estruturas geológicas possivelmente impõem uma maior restrição ao desenvolvimento dos processos fluviais, o que é refletido na morfologia da planície. O canal fluvial ativo é um pouco mais largo e menos sinuoso do que no trecho a montante.
Os maiores índices de sinuosidade do setor de montante, tanto do paleocanal como dos canais ativos, quando comparados ao setor de jusante revelam uma provável mudança de declividade do perfil longitudinal e na carga sedimentar do canal pré-urbano ou pré-atual. Estas mudanças podem ser decorrentes tanto de alterações no aporte sedimentar da bacia hidrográfica quanto de imposições de caráter estrutural (Ouchi 1985; Schumm 1963; Shumm et al. 2002), ou, ainda, devido aos dois tipos de eventos agindo em sinergia.

A análise da carta geomorfológica indica também que em algum momento do Pleistoceno Tardio ou já no Holoceno, o canal do rio Pinheiros apresentava menores larguras e maiores sinuosidades imediatamente à montante de uma região de falhas tectônicas e de afloramentos do embasamento pré-cambriano (Figura 8). Este estudo aponta para a interpretação de que estas discrepâncias morfológicas produzidas durante o Holoceno refletem condicionamentos estruturais, principalmente de caráter litológico, relacionados 
à disposição do embasamento subjacente por vezes aflorante na planície fluvial.

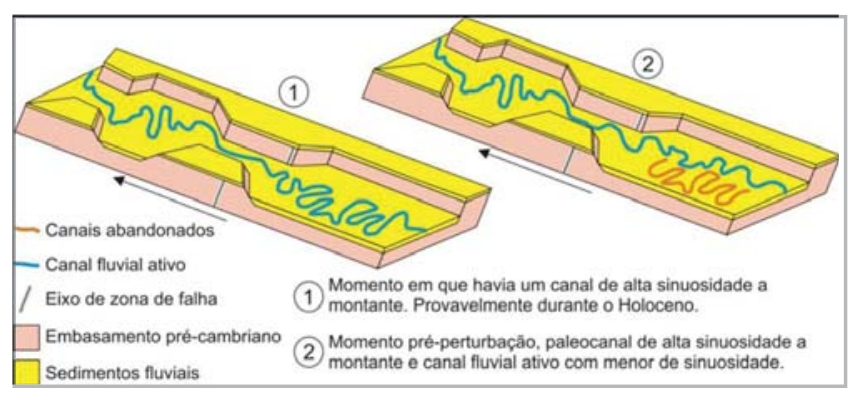

Figura 8 - Croquis esquemáticos da mudança de sinuosidade em trecho do canal do rio Pinheiros (evento de ocorrência provável no Holoceno)

Em algum momento anterior à instalação de sistema fluvial meândrico de deposição, provavelmente houve uma ação de incisão fluvial diretamente sobre as rochas do embasamento pré-cambriano. Posteriormente a este evento, instaurou-se um sistema fluvial entrelaçado pleistocênico correlativo à Formação Itaquaquecetuba. Por meio dos valores o do raio hidráulico deste paleocanal é possível supor que houve fluxos de maior energia que a do fluxo do canal holocênico (pré-urbano), e que este sistema, de maior energia, foi também responsável pela deposição da Formação Itaquaquecetuba.

\section{Conclusões}

A respeito de interpretações de ordem morfogenética, a carta produzida a partir da correlação de informações morfológicas e da caracterização dos materiais litológicos subjacentes, informações estas obtidas por pesquisa arquivística, permitiram a identificação de mudanças no sistema fluvial ocorridas durante o Pleistoceno Tardio e Holoceno, principalmente a partir da morfologia do canal fluvial ativo e de canais abandonados por avulsão.

O próprio canal fluvial ativo, nas fases pré-urbanas, apresentou diferenças morfológicas entre os compartimentos identificados. No trecho onde o canal atravessa o compartimento de falhas geológicas e afloramentos rochosos, o índice de sinuosidade apresenta um valor discretamente menor e a largura média um valor ligeiramente maior. Possivelmente a estrutura geológica ainda tenha exercido influência no Holoceno mais recente, em fases posteriores à avulsão, porém menos significativa do que no período anterior.

Estudos como este contribuem tanto para um melhor conhecimento da história natural de sítios urbanizados, colaborando em reconstruções paleogeográficas, morfogenéticas e de mudanças ambientais, como constitui base relevante para a realização de estudos de ordem aplicada, dentre os quais, os geotécnicos para implementação de obras em áreas urbanas.

A respeito da evolução de sistemas morfogenéticos, o estudo também permitiu apontar locais de importantes descontinuidades verticais e laterais entre os pacotes sedimentares que compõem a planície fluvial, auxiliando na revisão dos conhecimentos prévios sobre a estrutura geológica e as protuberâncias cristalinas basais da planície do Pinheiros (Ab'Saber 2007).

Do ponto de vista geotécnico, os contatos verticais e laterais como aqueles identificados neste tipo de reconstituição, podem ser interpretados como potencialmente problemáticos para estruturas construtivas (Douglas, 1985). Um exemplo na área de estudo que comprova esta possibilidade de aplicação de conhecimento foi o da identificação da arquitetura e das descontinuidades dos contatos entre depósitos tecnogênicos, sedimentos quaternários, e embasamento pré-cambriano com seus diferentes graus de intemperismo. Esse reconhecimento permitiu supor a forte influência destes pacotes e sua arquitetura no colapso ocorrido quando da instalação e uso de poço vertical na construção da Estação Pinheiros do Metrô ocorrido em janeiro de 2007. Esta estação e seu poço de acesso estão localizados exatamente numa importante descontinuidade lateral entre o embasamento pré-cambriano intemperizado e a Formação Itaquaquecetuba.

Pesquisas desta natureza auxiliam nas generalizações e extrapolações espaciais da provável arquitetura dos materiais de diversas gêneses, sendo os de origem antrópica considerados como parte desta arquitetura. Portanto, a carta geomorfológica da planície fluvial do rio Pinheiros adotando esta abordagem e focalizando estágios pré-perturbação, principalmente relativos ao Holoceno e ao Plesitoceno e, secundariamente voltada ao estágio antropogênico urbano, de intervalos históricos, possibilita a geração de produtos e de interpretações de grande utilidade no planejamento físicoterritorial urbano.

\section{Referências Bibliográficas}

Ab'Saber, A. N. Geomorfologia do sítio urbano de São Paulo. Cotia-SP: Ateliê Editoral, 1957. 349 p. Edição Fac-Similar 50 anos editada em 2007.

Ab'Saber, A. N. A estrutura da planície do Pinheiros: a Geologia da região do Butantã, em São Paulo, e o desastre recente nas obras do Metrô. Scientific American Brasil, Observatório, p. 98, mar. 2007.

Alcántara-Ayala I.; Goudie, A. Geomorphological hazards and disaster prevention. Cambridge: Cambridge University Press, 2010. 304 p. 
Arai, M.; Yamamoto, J. K. Datação da Formação Itaquaquecetuba. In: SIMPÓSIO DE GEOLOGIA DO SUDESTE, 4., 1995. Anais... São Pedro-SP: Sociedade Brasileira de Geologia, 1995, p. 84 .

Bridge, J. S. Rivers and Floodplains: Forms, Processes, and Sedimentary Record. Oxford: Blackwell Science Ltd., 2003. $504 \mathrm{p}$.

Carvalho, D. L. R. Indicadores geomorfológicos de mudanças ambientais no sistema fluvial do Alto Tietê (município de São Paulo): pesquisa documental. 2006. 2v. + anexos. Dissertação (Mestrado em Geografia Física) - Departamento de Geografia, FFLCH, USP, São Paulo. 2006.

Christofoletti, A. Geomorfologia. São Paulo: Edgar Blucher, 1974. 149 p.

Christofoletti, A. Geomorfologia fluvial. São Paulo: Edgar Blucher, 1981. 313 p.

Coltrinari, L. Um exemplo de carta geomorfológica de detalhe: a carta do médio vale do rio Parateí, SP. Revista do Departamento de Geografia, São Paulo, v. 1, p. 55-63, 1982.

Coltrinari, L. Cartas geomorfológicas. Orientação, São Paulo, n. 5, p. 96-99, 1984.

Coultard, J. P.; Pellerin, J.; Aguiar, M. B.; Coltrinari, L. Carta do modelado e das formações superficiais do médio vale do Parateí, SP. Sedimentologia e Pedologia, São Paulo, n. 9, p. $1-35,1978$.

Cunha, S. B. Geomorfologia Fluvial. In: Guerra, A. T.; Cunha, S. B. Geomorfologia: uma atualização e bases e conceitos. Rio de Janeiro: Bertrand Brasil, 1994. p. 211-252.

Dackombe, R. V.; Gardiner, V. Geomorphological field manual. London: George Allen \& Unwin, 1983. 254 p.

Démek, J. Generalization of Geomorphological Maps. In: Démek, J. Progress Made in Geomorphological Mapping. Brno, 1967. p. 36-72.

Douglas, I. The impact of urbanization on fluvial geomorphology in the humid tropics. Geo-eco-trop, n. 2, p. 229-242, 1978.

Douglas, I. The urban environment. London: Edward Arnold, 1983. $229 \mathrm{p}$.

Douglas, I. Geomorphology and urban development in the Manchester area. In: Johnson, R. H. The geomorphology of North West England. Manchester: Manchester University Press, 1985. p. 337-352.

Douglas, I.; Lawson, N. The human dimensions of geomorphological work in Britain. Journal of Industrial Ecology, v. 4, n. 2, p. 9-33, 2000.

Empresa Paulista de Planejamento Metropolitano (EMPLASA). Mapa da Região Metropolitana de São Paulo. Sistema Cartográfico Metropolitano, São Paulo, 1972/74/80/81. Escala $1: 10.000$.
Empresa Paulista de Planejamento Metropolitano (EMPLASA). Carta Geológica da Região Metropolitana de São Paulo. Folha: São Paulo, São Paulo, 1984. Escala: 1:50.000.

Estaiano, J. C. Impactos da mineração de areia em planícies fluviais meândricas da bacia hidrográfica do Alto Tietê: o caso do rio Embu-Guaçu, São Paulo - SP. 2007. 185 f. Dissertação (Mestrado em Geografia Física) - Departamento de Geografia, FFLCH, USP, São Paulo. 2007.

Goudie, A. S. The Human Impact Reader: readings and case studies. Oxford: Blackwell, 1997. 472 p.

Goudie, A. Encyclopedia of Geomorphology. $2^{\text {a }}$ Ed. London e New York: Taylor \& Francis e-library, 2006. 1156 p.

Gregory, K. J.; Walling, D. E. (eds.) Human activity and environmental processes. Chichester and New York: Wiley, 1987. $466 \mathrm{p}$.

Gupta, A. Geoindicators for tropical urbanization. Environmental Geology, v. 42, issue 7, p. 736-742, 2002.

Gupta, A.; Ahmad, R. Geomorphology and the urban tropics: building an interface between research and usage. Geomorphology, v. 31, issues 1-4, p. 133-149, 1999.

Gurnell, A. M.; Peiry, J. L; Petts, G. E. Using Historical Data in Fluvial Geomorphology. In: Kondolf, G. M.; Piégay, H. (eds.) Tools in Fluvial Geomorphology. Chichester, UK: John Wiley \& Sons, Ltd., 2003. p. 77-101.

Hart, M. G. Geomorphology pure and applied. London: George Allen \& Unwin, 1986. 228 p.

Hasui, Y.; Sadowsky, G. R. Evolução geológica do PréCambriano na região sudeste do Estado de São Paulo. Revista Brasileira de Geociências, v. 6, n. 2, p. 182-200, 1976.

Hasui, Y.; Carneiro, C. D. R. Origem e evolução da Bacia Sedimentar de São Paulo. In: Associação Brasileira de Geologia de Engenharia; Sociedade Brasileira de Geologia. Aspectos geológicos e geotécnicos da bacia sedimentar de São Paulo (Mesa redonda), São Paulo, Publicação especial, 1980. p. $5-13$.

Knigthon, D. Fluvial forms and processes: a new perspective. London and New York: Arnold, 1998. 383 p.

Lima, C. R. Urbanização e intervenções no meio-físico na borda da Bacia Sedimentar de São Paulo: uma abordagem geomorfológica. 1990. 105 f. Dissertação (Mestrado em Geografia Física) - Departamento de Geografia, FFLCH, USP, São Paulo, 1990.

Miall, S. A. The Geology of fluvial deposits: sedimentary facies, basin analysis and petroleum geology. New York, Heidelberg, Berlin: Spring-Verlag, 1996. 582 p.

Nir, D. Man, a geomorphological agent: an introduction to Anthropic Geomorphology. Boston: D. Reidel publishing Co.; Jerusalem: Keter publishing house, 1983. 165 p. 
Ouchi, S. Response of alluvial rivers to slow active tectonic movement. Geological Society of America Bulletin, v. 96, n. 4, p. 504-515, 1985.

Riccomini, C.; Coimbra, A. M.; Takiya, H. Tectônica e sedimentação na Bacia de São Paulo. In: Associação Brasileira de Águas Subterrâneas; Associação Brasileira de Geologia de Engenharia; Sociedade Brasileira de Geologia. Problemas geológicos e geotécnicos na Região Metropolitana de São Paulo, São Paulo, 1992. p. 21-45.

Riccomini, C.; Santa'Anna, L. G.; Ferrari, A. L. Evolução geológica do Rift Continental do Sudeste do Brasil. In: MantessoNeto, V.; Bartorelli, A.; Carneiro, C. D. R.; Brito-Neves, B. B. (orgs.) Geologia do continente Sul-americano: Evolução da obra de Fernando Flavio Marques de Almeida. São Paulo: Beca, 2004. p. 383-405.

Rodrigues, C. On antropogeomorphology. In: REGIONAL CONFERENCE ON GEOMORPHOLOGY, 1999, Anais... Rio de Janeiro, International Association of Geomorphologists, 1999, p. 100-110.

Rodrigues, C. Documentos geográficos: arquivos de fotos aéreas como opção de pesquisa. Memória e Energia, n. 28, p. 26-41, 2001.

Rodrigues, C. A urbanização da metrópole sob a perspectiva da geomorfologia: tributo a leituras geográficas. In: Carlos, A. F. A.; Oliveira, A. U.. Geografias de São Paulo: representação e crise da metrópole. São Paulo: Contexto, 2004. p. 89-114.

Rodrigues, C. Morfologia original e morfologia antropogênica na definição de unidades espaciais de planejamento urbano: Exemplo na metrópole paulista. Revista do Departamento de Geografia, v. 17, p. 101-111, 2005.

Santana, C. L. Geomorfologia da planície fluvial do rio Ribeira de Iguape entre Sete Barras e Eldorado (SP): subsídios ao planejamento físico-territorial de áreas inundáveis. 2008. 201 $\mathrm{f}+$ anexos. Dissertação (Mestrado em Geografia Física) Departamento de Geografia, FFLCH, USP, São Paulo. 2008.

Santos, E. Tietê, o rio de São Paulo. In: Azevedo, A. A Cidade de São Paulo. São Paulo: Cia. Editora Nacional, v. 1, 1958. p. 45-66.
Santos, D. B; Garcia, M. J.; Saad, A. R.; Bistrichi, C. A. Palinoestratigrafia da Formação Itaquaquecetuba, Bacia de São Paulo, Brasil. Revista Brasileira de Paleontologia, v. 13, n. 3, p. 205-220, 2010.

Santos, M. L., Stevaux, J. C., Gasparetto, N. V. L., Souza filho, E. E. S. Geologia e geomorfologia da planície aluvial do rio Ivaí em seu curso inferior. Revista Brasileira de Geomorfologia, v 9, n. 1, p. 23-34, 2008.

Sara Brasil S/A. Mappa Topographico do Município de São Paulo. Roma: Instituto Geográfico de Agostini, Folha III, 1930. Escala 1:2000.

Savigear, R. A. G. A Technique of morphological mapping. Annals of Association of American Geographers, v. 55, n. 3, p. 66-75, 1965.

Schumm, S. A. Sinuosity of alluvial rivers on the great plains. Geological Society of America Bulletin, v. 74, n. 9, p. 10891100, 1963.

Schumm, S. A.; Dumont, J. F.; Holbrook, J. M. Active tectonics and alluvial rivers. Cambridge: Cambridge Univ. Press, 2002. $296 \mathrm{p}$.

Suguio, K.; Bigarella, J. J. Ambientes fluviais. $2^{\text {a }}$ Ed. Revisada, Florianópolis: Ed. da UFSC e Ed. da UFPR, 1990. 183 p.

Takiya, H. Estudo de Sedimentação Neogênico Quaternário no Município de São Paulo: Caracterização dos depósitos e suas implicações na geologia urbana. 143 f. 1997. Tese (Doutorado em Geociências) - Instituto de Geociências, USP, São Paulo, 1997.

Tricart, J. Principes et méthodes de la géomorphologie. Paris: Mas. et Cie. Éditeurs, 1965. 469 p.

Trimble, A. W. The use of historical data and artifacts in geomorphology. Progress in Physical Geography, v. 1, n. 32, p. 3-29, 2008. 